\title{
Apomictic parthenogenesis and genotypic diversity in Cypridopsis vidua (Ostracoda: Cyprididae)
}

John E. Havel and

Paul D. N. Hebert
Department of Biological Sciences, University of Windsor, Windsor, Ontario, N9B 3P4, Canada.

Based on sex ratios, the crustacean subclass Ostracoda appears to have made frequent transitions from sexual to asexual reproduction. However few genetic data are available verifying their mode of reproduction. The current report provides such evidence for apomictic pathenogenesis in the cosmopolitan cypridid ostracode Cypridopsis vidua. Sex ratio analysis indicated that natural populations are exclusively female. Allozyme phenotypes in 18 of 20 natural populations showed strong departures from Hardy-Weinberg expectations at single loci, and three of four populations had non-random associations of phenotypes at MPI and PGM. Allozyme phenotypes at these loci suggested that polyploids were present in half these populations and were more common in the low arctic site than in the temperate sites. Most natural populations of $C$. vidua displayed high levels of genotypic diversity, with a total of 77 unique clones detected and up to 24 clones per pond. Breeding studies on 64 isofemale lines established that parthenogenesis is apomictic and that mutation rates are less than $10^{-3}$.

\section{INTRODUCTION}

Although sexual reproduction is the dominant breeding mode, asexual reproduction is widespread in both plant and animal kingdoms (Bell, 1982; Ellstrand and Roose, 1987). Since genetic recombination is absent, early theorists assumed that genetic variation would be low in asexuals (Williams, 1975). However, a variety of studies have now shown that this view is incorrect. Studies of morphological, chromosomal, allozymic, and histocompatibility diversity have revealed abundant variation on both macro- (Lyman and Ellstrand, 1984; Hebert et al., 1988) and microgeographic scales (Hebert and Crease, 1980; Hoffmann, 1986; Ellstrand and Roose, 1987).

Species of the crustacean subclass Ostracoda apparently employ both breeding modes. Based on the presence or absence of males, both asexual and sexual species are common in freshwater habitats (Tressler, 1959; Bell, 1982). Four genera include exclusively asexual species, three exclusively sexual species, while 14 include species employing both breeding systems. In contrast, most marine species are believed to be sexual (Bell, 1982). Its broad taxonomic distribution suggests that asexuality has evolved many different times in this group. Since ostracodes are cosmopolitan and live in a wide variety of habitats, this group should provide useful insight into the evolution of sex and factors maintaining genotypic diversity.

Previous genetic work on ostracodes has been limited. Cytogenetic work of Bauer (1940) established differences in chromosomal behaviour between parthenogenetic and sexual "races" of Heterocypris incongruens, and Tetart's (1978) study of 24 freshwater ostracode species from France confirmed that the majority of species reproduced asexually, with several asexuals exhibiting cytological variation. Sywula and Lorenc (1982) studied esterase polymorphisms in Cyprinotus incongruens, but the genetic basis of the variation they found was uncertain. Allozyme studies on other ostracode species were unsuccessful due to their small size (Sywula et al., 1985). Recently, cellulose acetate electrophoresis has provided an improved method for assaying allozyme diversity in small organisms (Easteal and Boussy, 1987), and has, in the present study, permitted the resolution of multiple enzymes from very small ostracodes.

The current study examines the extent of clonal diversity in natural populations of the freshwater cypridid Cypridopsis vidua (O. F. Muller 1776) 
Brady 1867 , and supplements this with laboratory studies to confirm its mode of reproduction. Although early workers suggested that this species was a cyclic parthenogen (Weismann, 1880, cited in Kesling, 1951), subsequent laboratory studies and numerous collections from natural populations have failed to detect males, leading recent workers to assume the species is asexual. C. vidua is nearly cosmopolitan in distribution, being reported from North America, Europe, Africa, and South America (Kesling, 1951). The other 15 species of Cypridopsis in North American are less widely distributed, with most being reported from a single state or province. Seven of these species are sexual and are presently restricted to localities in the gulf states and Mexico (Tressler, 1959; Ferguson, 1964), although Delorme (1970) reported fossil records of one sexual species (C. okeechobei) from the Canadian prairies. The eight other asexual species are endemic to either northern or southern locales.

\section{MATERIALS AND METHODS}

\section{Collections}

Ostracodes were collected from ponds and lakes between May 1987 and August 1988 by sweeping a $200 \mu \mathrm{m}$-mesh hand net through macrophytes and along the bottom. Lake collections were restricted to the littoral zone. Samples were sorted on a light box and C. vidua identified using Tressler (1959). Collections were made in Manitoba, Ontario, Quebec, New Brunswick, Wisconsin, Michigan, and Texas. C. vidua was collected during March in Texas, July-August in Manitoba, and May-June in the remainder of the sites. C. vidua were held alive at $4^{\circ} \mathrm{C}$ for one week or less prior to electrophoresis, or otherwise frozen at $-70^{\circ} \mathrm{C}$. Samples from half the populations were examined for males at $100 \times$ by crushing 20 individuals under a cover slip. Males of other species can be recognized by the presence of sperm tubes, ejaculatory ducts, or hemipenes, mature females by ovaries and eggs (Tressler, 1959; personal observation).

\section{Allozyme variation}

Electrophoresis was carried out on Titan III cellulose acetate gels (Helena Laboratories, Beaumont, Texas) and Tris Glycine buffer $(3 \mathrm{~g}$ Trizma base, $14 \cdot 4 \mathrm{~g}$ glycine, 1 litre water; $p \mathrm{H} 8 \cdot 5)$. Gels were presoaked and run in the same buffer solution. Cypridopsis were crushed individually in sample wells and 12-24 samples applied to each gel. Gels were run for 15 minutes at $200 \mathrm{~V}(2 \mathrm{~mA}$ per gel plate), then stained using standard methods (Harris and Hopkinson, 1976).

Two populations (Baseline-2, near Windsor, Ontario, and T78, near Churchill, Manitoba) were screened for variation at 15 enzymes. Four enzymes were monomorphic, five were polymorphic but unreliable, and four did not stain. Two enzymes were polymorphic and readily scored for allozyme variation: mannose phosphate isomerase (MPI) and phosphoglucomutase (PGM). As a result, other populations were scored only for MPI and PGM.

Alleles were designated by their relative migration rates: 0 fastest, 7 slowest. Although the genetic basis of allozyme variation could not be verified with breeding studies because of $C$. vidua's asexual mode of reproduction, banding patterns for putative heterozygotes were consistent with their known quaternary structure (both MPI and PGM monomeric; Harris and Hopkinson, 1976). After establishing laboratory cultures, all subsequent gel plates included 2-4 individuals from clones of known genotype to act as standards.

Allozyme data were collected on 23 populations and genotypic frequencies at single polymorphic loci were tested for fit to Hardy-Weinberg (HW) expectations using $\chi^{2}$ tests. Loci were considered polymorphic if the frequency of the most common allele was less than 0.90 and sample size exceeded 20. Rare classes were pooled so that minimum expected values exceeded five. Threebanded and unbalanced phenotypes were pooled with the closest two-banded phenotype for HW analysis. Two-locus genotypes were examined for deviation from random association by G-tests of independence (Sokal and Rohlf, 1981).

Genotypic diversity was estimated by two different statistics. The first was the total number of multilocus genotypes (clones, $k$ ) identified in each sample. The second statistic was observed genotypic diversity $\left(G_{0}\right.$, Hoffmann, 1986), which combines estimates of clonal abundance with evenness.

$$
G_{0}=1 / \sum_{i=1}^{k} g_{i}^{2}
$$

where $g_{i}$ is the frequency of the $i$ th of $k$ genotypes. The range of $G_{0}$ is 1 to $k$, with $G_{0}$ reaching its maximum value when the clonal frequencies are all equal.

Clonal composition and distribution were compared among 19 populations for which standard markers were included on gels. 


\section{Breeding study}

For a direct test of apomictic parthenogenesis, 126 cultures were initiated with adult $C$. vidua collected from nine locations. These were placed individually in $120 \mathrm{ml}$ cups containing synthetic pond water (Hebert and Crease, 1980) and masscultured green algae (primarily Ankistrodesmus sp. and Chlorella sp.). After 3 months, 64 cultures contained abundant $C$. vidua, and were likely mixtures of several generations (Kesling, 1951). Ten individuals from each of the 64 cups were examined at $100 \times$ for males. MPI and PGM phenotypes were determined for eight additional individuals from each cup to ascertain whether isofemale lines were composed of genetically identical individuals.

\section{RESULTS}

\section{Collections}

Sufficient numbers of $C$. vidua for genetic study were collected from 23 populations over a wide geographic range, extending from southern Texas to northern Manitoba (fig. 1, table 1). Microscopic examination of adults from 12 different collections revealed only females, as did repeated observations of cultured animals.

\section{Allozyme variation}

Allozyme studies revealed abundant variation in C. vidua. Seven alleles were detected at MPI, with a mean of 4.4 alleles per population, and 5 alleles at PGM, with a mean of $2 \cdot 3$ alleles (table 2). In most cases, heterozygotes had two bands of equal staining intensity. However, in ten populations some MPI and PGM phenotypes were either threebanded or had unbalanced activity, with one zone staining at least twice as intensely as the other (tables 1 and 2). The incidence of these phenotypes appeared to be higher in arctic than temperate populations, with values ranging from 0.06 to 0.15 near Windsor and 0.19 to 0.51 near Churchill (Wilcoxin Rank Sum Test, $W=40, P=0.004$ ). None of the four lake populations included any of these phenotypes, though these populations were polyclonal (table 1).

At single polymorphic loci, 18 of 20 populations showed significant departures from HWE at 1 or more loci (table 1). Direction of departure was estimated by the inbreeding coefficient, $F_{i}=$ $1-H_{0} / H_{\mathrm{e}}$, where $H_{0}$ and $H_{\mathrm{e}}$ are the number of heterozygotes observed and expected under HWE.
There was no evidence of consistent heterozygote excess or deficiency, as $F_{i}$ values included similar numbers of positive and negative values (15 and $11)$ and were not significantly different from zero (Wilcoxin Signed Rank Test, $T=0 \cdot 37, P>0 \cdot 50$ ).

In four populations both loci were sufficiently polymorphic so that it was possible to test for deviations from random association of genotypes (following pooling of rare classes). These tests indicated that genotypes at the two loci were nonrandomly associated in three of the four populations and in the 19 populations pooled (table 3 ).

\section{Clonal diversity}

A total of 77 different clones were detected among the 842 animals analysed, with a mean of $8 \cdot 3$ clones per pond (table 2). Although many ponds were multiclonal, four ponds were uniclonal. Two of these ponds shared the same clone and were from eastern Canada. Since clonal frequencies were uneven within populations, the genotypic diversity measure $\left(G_{0}\right)$ was usually much less than the observed number of clones (table 2). The effective number of clones in each population ranged from 1 to $10 \cdot 7$, with an average of $3 \cdot 8$.

Comparison of clonal genotypes among populations was carried out on 19 of the 23 populations. The studies showed that most clones were rare, with 48 of the 77 clones found in only a single location (fig. 2). However, some clones were apparently widely distributed. For instance, clone 23-33 (MPI-PGM) was found in 12 of the 19 populations and distributed from northern and eastern Canada to southern United States (table 2).

Although most populations were sampled only once, the Warner Road population was sampled twice in 1988, and these samples had significantly different clonal arrays $(G=22 \cdot 6,4 \mathrm{df}, P<0 \cdot 005)$. The 6 April sample contained only juveniles, with 6 clones detected in 20 animals surveyed, while in the 10 May sample 14 clones were detected in 47 animals surveyed. In addition to additional rare clones detected in the larger sample, two new genotypes were in high abundance (frequencies $0 \cdot 17$ and $0 \cdot 23$ ).

\section{Breeding study}

Microscopic examination of samples from each of the 64 laboratory cultures showed only females, with most of the adults carrying eggs. Allozyme studies indicated no genotypic variation within these cultures. Most cultures contained heterozygotes for at least one locus, so the absence of 


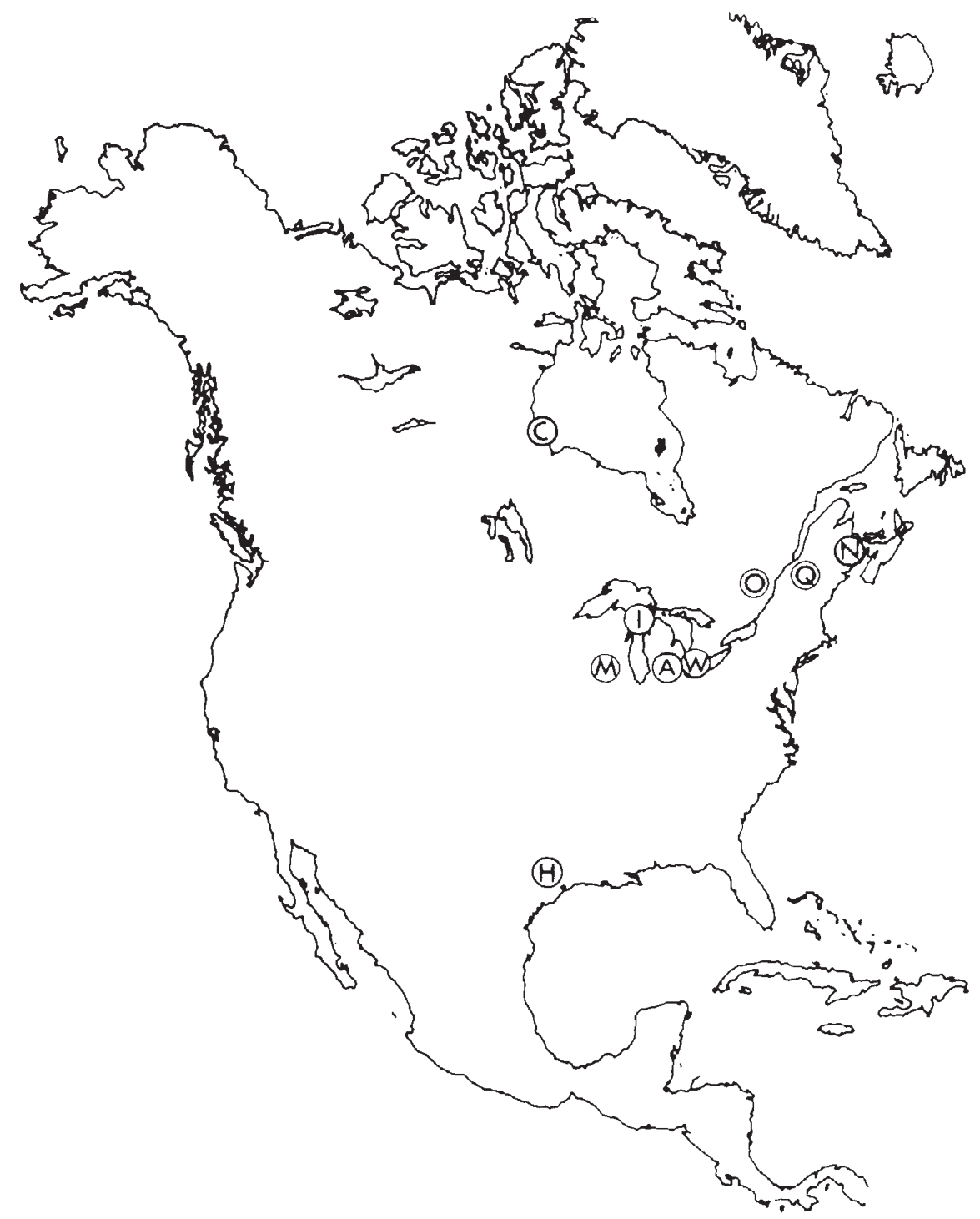

Figure 1 Locations sampled. $\mathrm{A}=$ Ann Arbor, Michigan; $\mathrm{C}=$ Churchill, Manitoba; $\mathrm{H}=$ Houston, Texas; $\mathrm{I}=\mathrm{Isabella,} \mathrm{Michigan;}$ $\mathrm{M}=$ Madison, Wisconsin; $\mathrm{N}=$ Moncton, New Brunswick; $\mathrm{O}=$ Crosby, Ontario; $\mathrm{Q}=$ St. Rose, Quebec; $\mathrm{W}=\mathrm{Windsor}$ and Rondeau Park, Ontario.

recombination was convincing (table 4). Since eight individuals were electrophoresed from each culture, the chance of detecting no recombinants in individual cultures if segregation was occurring would be small $\left((0 \cdot 5)^{8}=0 \cdot 004\right)$. The absence of recombination among all the cultures carries an extremely small joint probability (table 4).

\section{DISCUSSION}

The current study confirms that $C$. vidua from North America breeds by apomictic partheno- genesis. In congruence with prior studies (Kesling, 1951), no males were observed in natural or laboratory populations. Genetic data confirm the asexual mode of reproduction. Genotypic frequencies in 18 of 20 natural populations were out of HWE and linkage disequilibrium between genotypes at MPI and PGM was frequent. Similar genotypic characteristics have been reported in studies of other asexual taxa (Hoffmann, 1986; Innes et al., 1986). The laboratory rearing studies indicated that single C. vidua females could initiate cultures and that their offspring were genetically identical. The lack 
Table 1 Summary of allozyme results for populations of Cypridopsis vidua. Populations examined for sex ratios (f). Proportion of individuals with 3-banded or unbalanced phenotypes: prop. polypl. $\chi^{2}$ values were tested for fit to HWE at indicated degrees of freedom (df); probability values $(P)$ : ns $P>0.05,{ }^{*} P<0.05,{ }^{*} P<0.01 ;$ - not sufficiently polymorphic or insufficient data to test

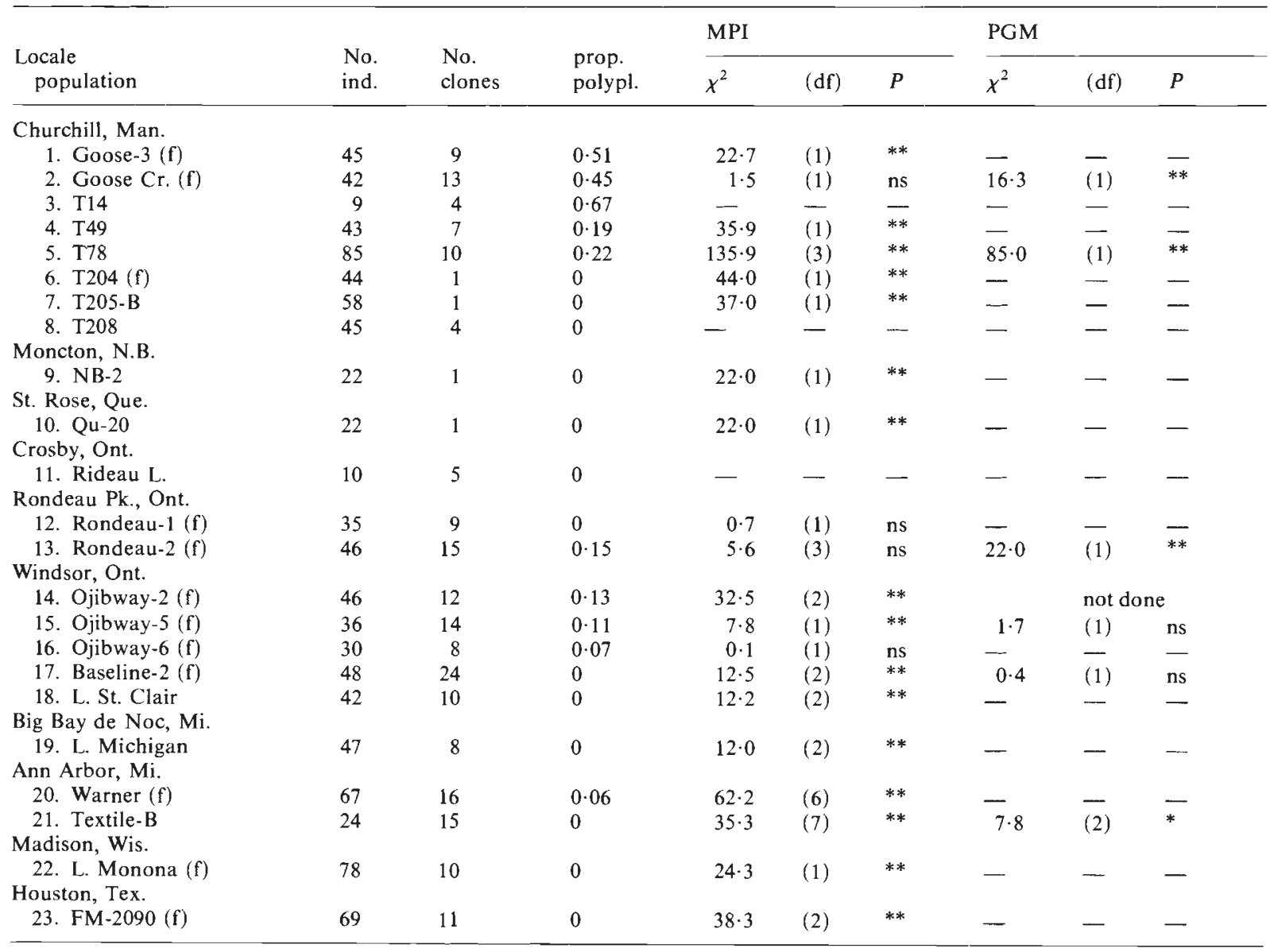

of segregation at heterozygous loci confirms that eggs are produced apomictically in this taxon. These data are the first genetic confirmation of asexual reproduction in an ostracode, and suggest that other species in which males have not been found are also apomicts.

Eleven populations of $C$. vidua included individuals with 3-banded or unbalanced phenotypes at the monomeric loci MPI and PGM. Such phenotypes are ordinarily indicative of polyploidy (Weider and Hebert, 1987; Beaton and Hebert, 1988), but DNA quantification and cytological studies are necessary to verify the polyploid status of the clones in C. vidua. There is little prior evidence of polyploidy in ostracodes, although Tetart's (1978) cytological studies revealed a low proportion of triploids in one of 17 asexual ostracode species he examined. The allozyme data for $C$. vidua suggest there may be a latitudinal pattern in polyploidy, with the lowest incidence in the south and highest in the north. In temperature latitudes, it appears that polyploids are more common in ponds than in lakes.

The current study revealed surprisingly high levels of genotypic diversity in $C$. vidua. Based on only two polymorphic loci, up to 24 clones were detected in single ponds (average $8 \cdot 3$ ). Such high clonal diversity is unprecedented for asexuals living in discrete habitats. For example, in a survey of obligately asexual Daphnia pulex from ponds near Churchill, Manitoba, one to four clones were detected per pond (average 1.5 ) and only 16 in the entire region (Weider and Hebert, 1987). Surveys of the same species throughout the Great Lakes 


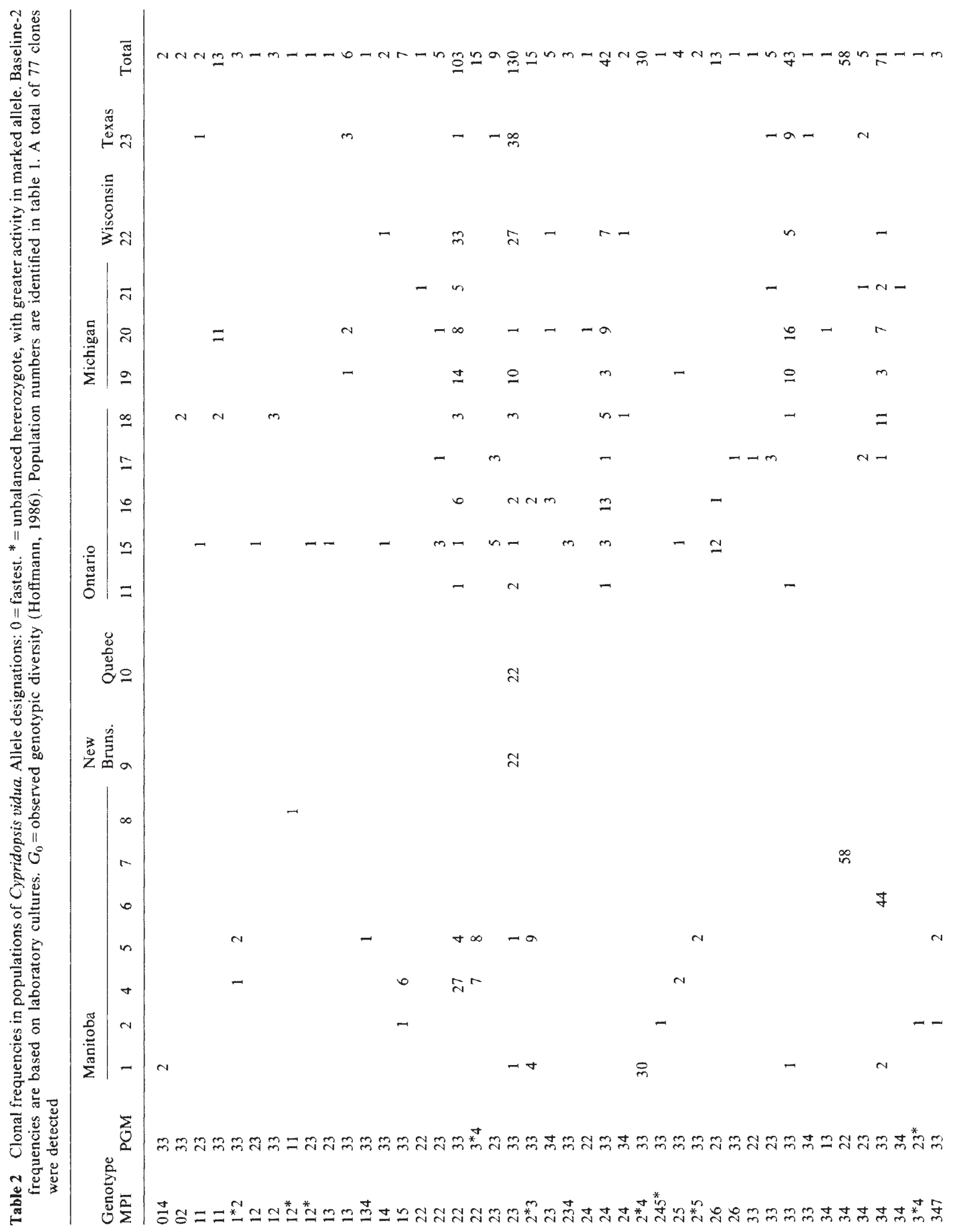




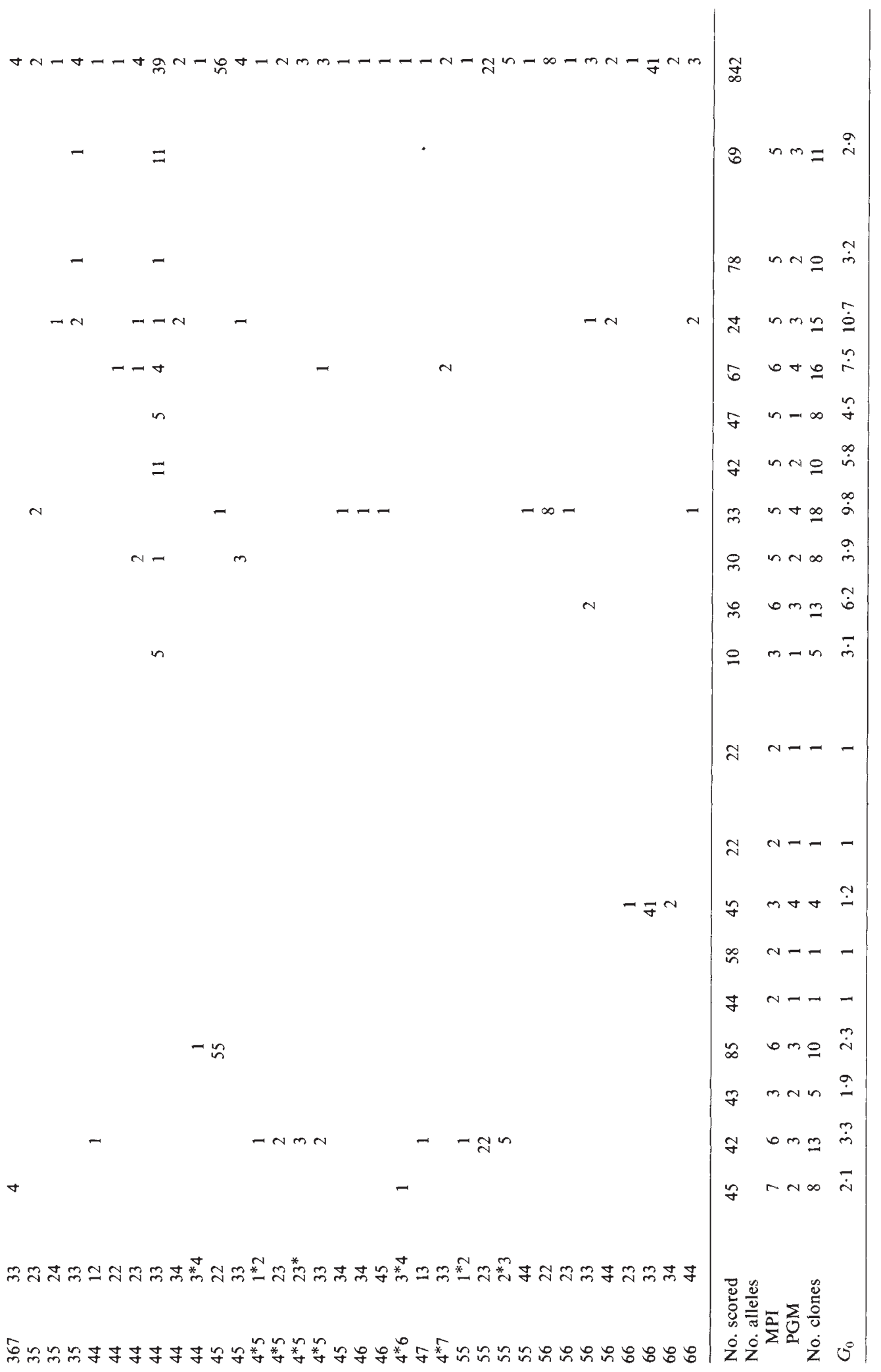


Table 3 G-tests of independence between MPI and PGM phenotypes following pooling of rare classes. Pooled data are from all 19 populations in table 2

\begin{tabular}{lrll}
\hline Population & $G$ & df & $P$-value \\
\hline Goose Cr. & $22 \cdot 3$ & 4 & $<0.005$ \\
T78 & $116 \cdot 3$ & 4 & $<0.005$ \\
Ojibway-5 & $5 \cdot 8$ & 2 & $<0 \cdot 10$ \\
Baseline-2 & $10 \cdot 2$ & 3 & $<0.05$ \\
\hline Pooled & $19 \cdot 6$ & 5 & $<0.005$ \\
\hline
\end{tabular}

watershed revealed an average of only $2 \cdot 8$ clones per pond (Hebert et al., 1988). One to nine clones per population were detected in the brine shrimp Artemia parthenogenetica (Abreu-Grobois and Beardmore, 1982), while a total of three hemiclones were detected in 13 populations of the hybridogenetic triploid fish Poeciliopsis monacha lucida (Vrijenhoek, 1978).

Seventy-seven clones of C. vidua were detected in the 23 ponds surveyed. Several clones were apparently widespread, with one ranging from Churchill, Manitoba, to Houston, Texas. However with clonal discrimination based on only two loci, it is likely that this "clone" represents a clonal complex whose members happen to share a common genotype at these loci, while differing at other loci. The number of $C$. vidua clones detected is almost certainly a small fraction of the total present (Hebert et al., 1988).

The proximate cause of the high clonal diversity in $C$. vidua is unclear. Two problems need to be considered: the origin of diversity in single habitats and the origin of diversity in the entire gene pool. Potential sources of diversity in single habitats include mutational or recombinational diversification of single colonists and multiple colonizations of the habitat. The results from the

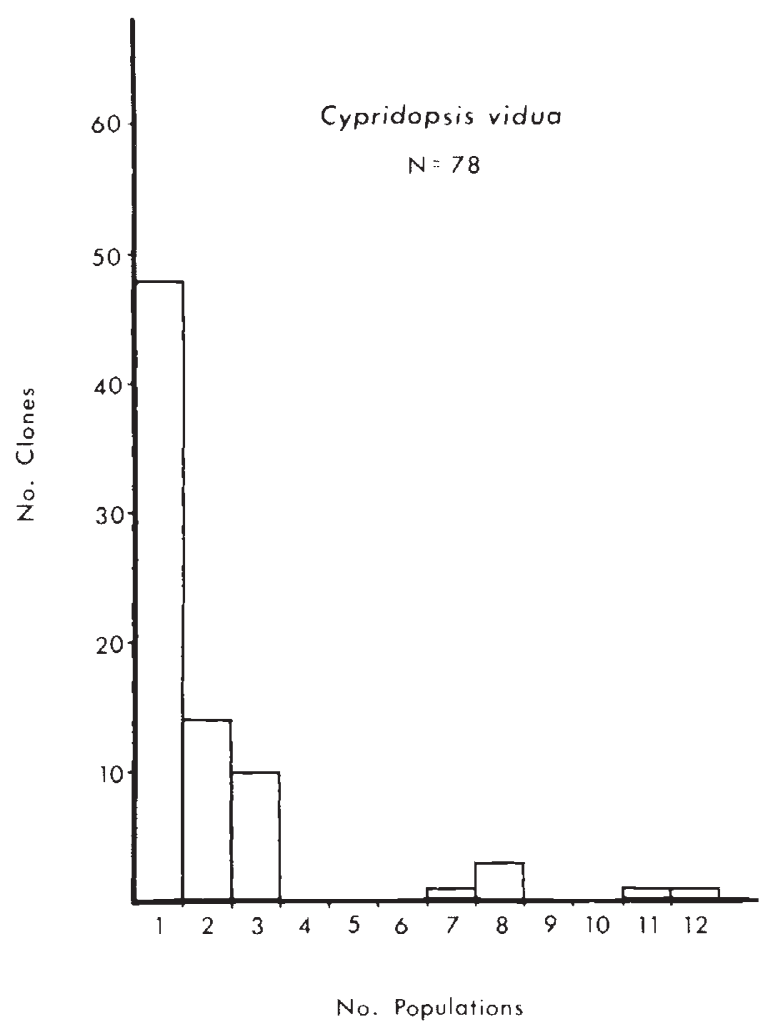

Figure 2 Histogram showing the number of populations in which each clone was detected. Raw data are presented in table 2 .

current breeding study suggests that $C$. vidua does not have exceptionally high mutation or recombination rates during subitaneous egg formation. The lack of variation within the lab cultures indicated that recombination rates were no higher than $1.9 \times$ $10^{-3}$ (67 total heterozygous loci $\times 8$ individuals) and mutation rates no higher than $4.9 \times 10^{4}(64$

Table 4 Allozyme results from C. vidua cultures. Eight individuals from each culture were electrophoresed at MPI and PGM

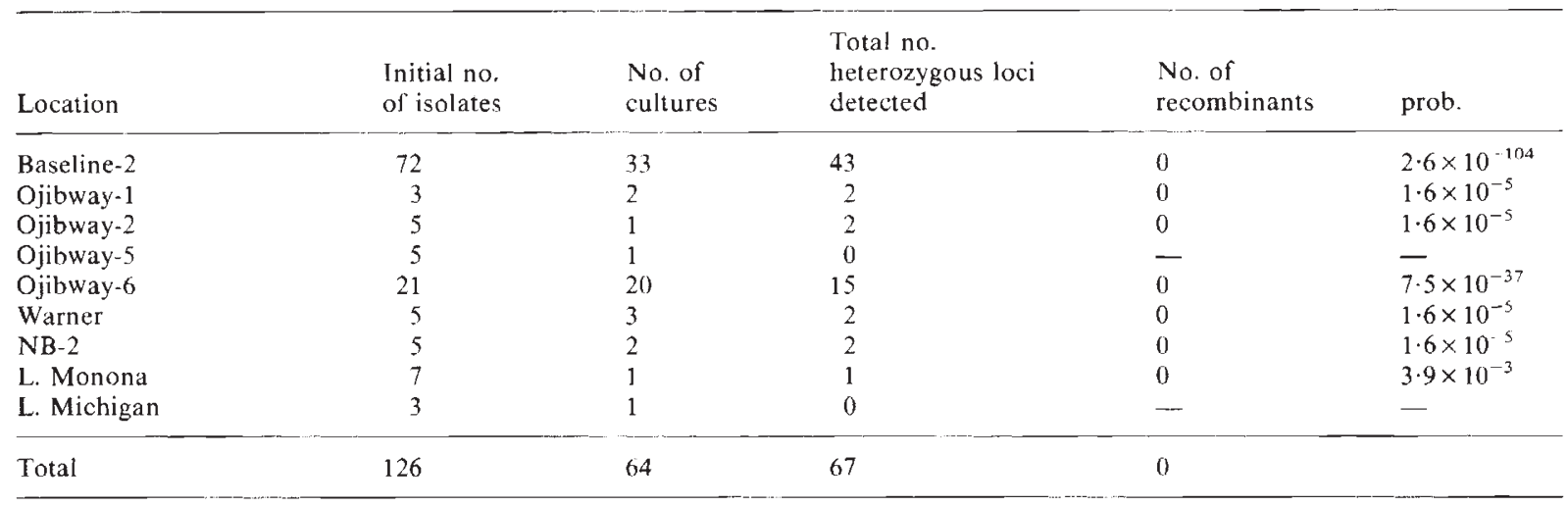


cultures $\times 2$ loci $\times 8 \times 2$ alleles) (table 4 ). There is a clear need to extend such studies to investigate mutation and recombination rates among the progeny of resting eggs. Rare endomeiosis during resting egg oogenesis could, for example, account for the large number of genotypic combinations observed in the present study. Rare production of males would have a similar effect, but extensive field surveys have never detected males in this species (Furtos, 1933; Kesling, 1951; Delorme, 1970). Multiple colonizations of each habitat could also account for the high clonal diversity in local habitats. Two vectors for gene flow have been identified for $C$. vidua: adults can remain alive following passage through the guts of fish (Vinyard, 1979) and eggs hatch following passage through the guts of ducks (Proctor, 1964).

Polyphyletic origins of asexuality have been shown to be a cause of high clonal diversity in other asexual species (Harshman and Futuyma, 1985; Hebert 1987). This mechanism is probably not currently important in $C$. vidua, as this study examined populations over a wide geographic range and found no evidence of conspecific sexual populations. However, sexual species in the genus Cypridopsis presently co-occur with $C$. vidua in the Gulf States (Tressler, 1959; Ferguson, 1964) and such co-occurence may have been broader in the past (Delorme, 1970). Mating between congenerics is a source of variation in some asexual fish (Vrijenhoek, 1978), and remains a potential source of high genotypic diversity in C. vidua.

In summary, the current study confirms apomixis in C. vidua and suggests that polyploidy is widespread, with a high incidence in arctic populations. The levels of genotypic diversity detected in this species are higher than that of other asexuals living in discrete habitats. The broad geographic distribution of $C$. vidua may be a consequence of this high diversity.

Acknowledgements We are grateful to Rachelle Masse and Terrie Finston for maintaining the cultures, Denis Delorme for confirming identifications, and Marc Boileau for contributing the Houston sample. Larry Weider and an anonymous reviewer made helpful comments on the manuscript. Financial support was provided by a grant from the Natural Sciences and Engineering Research Council of Canada to PDNH.

\section{REFERENCES}

ABREU-GROBOIS, F. A. AND BEARDMORE, J. A. 1982. Genetic differentiation and speciation in the brine shrimp Artemia. In Berigozzi, C. (ed.) Mechanisms of Speciation, Alan R. Liss, Inc., New York, pp. 345-376.
BAUER, H. 1940. Über die Chromosomen der bisexuellen und der parthenogenetischen Rasse des Ostracoden Heterocypris incongruens Ramd. Chromosoma, 1, 620-637.

BEATON, M. J. AND HEBERT, P. D. N. 1988. Geographic parthenogenesis and polyploidy in Daphnia pulex (Leydig). Am. Nat., 132, 837-845.

BELL, G. 1982. The Masterpiece of Nature: The Evolution and Genetics of Sexuality. University of California Press, Berkeley.

DELORME, L. D. 1970. Freshwater ostracodes of Canada. Part II. Subfamily Cypridopsinae and Herpetocypridinae, and family Cyclocyprididae. Can. J. Zool., 48, 253-266.

EASTEAL, S. AND BOUSSY, I. A. 1987. A sensitive and efficient isoenzyme technique for small arthropods and other invertebrates. Bull. ent. Res., 77, 407-415.

ELlSTRAND, N. C. AND ROOSE, M. L. 1987. Patterns of genotypic diversity in clonal plant species. Amer. J. Bot., $74,123-131$.

FERGUSON, E. 1964. The ostracod (Crustacea) genus Cypridopsis in North America and a description of Cypridopsis howei, Sp. Nov. Trans. Amer. Micros. Soc., 83, 380-384.

FURTOS, N. C. 1933. The Ostracoda of Ohio. Ohio Biol. Survey, $5,411-524$

HARRIS, H. AND HOPKINSON, D. A.1976. Handbook of Enzyme Electrophoresis in Human Genetics. North-Holland Publ., Amsterdam.

HARSHMAN, L. G. AND FUTUYMA, D. J. 1985. The origin and distribution of clonal diversity in Alsophila pometaria (Lepidoptera: Geometridae). Evolution, 39, 315-324.

HEBERT, P. D. N. 1987. Genotypic characteristics of the Cladocera. Hydrobiologia, 145, 183-193.

HEBERT, P. D. N. AND CREASE, T. J. 1980. Clonal coexistence in Daphnia pulex: another planktonic paradox. Science, 207, 1363-1365.

HEBERT, P. D. N., WARD, R. D. AND WEIDER, L. J. 1988. Clonal diversity patterns and breeding system variation in Daphnia pulex, an asexual-sexual complex. Evolution, 42, 147-159.

HOFFMANN, R. J. 1986. Variation in contributions of asexual reproduction to the genetic structure of populations of the sea anemone Metridium senile. Evolution, 40, 357-365.

INNES, D. J., SCHWARTZ, S. S. AND HEBERT, P. D. N. 1986. Genotypic diversity and variation in mode of reproduction among populations in the Daphnia pulex group. Heredity, $57,345-355$.

KESLING, R. V. 1951. The morphology of ostracod molt stages. Ill. Biol. Monogr., 21, 1-324.

LYMAN, J. C. AND ELLSTRAND, N. C. 1984. Clonal diversity in Taraxacum officinale (Compositae), an apomict. Heredity, $53,1-10$.

PROCTOR, V. W. 1964. Viability of crustacean eggs recovered from ducks. Ecology, 45, 656-658.

SOKAL, R. R. AND ROHLF, F. J. 1981. Biometry. W. H. Freeman, San Francisco.

SYWULA, T., AND LORENC, R. 1982. Esterase polymorphism as a marker of interpopulation differentiation in Cyprinotus incongruens (Ramd.) (Ostracoda, Crustacea). Bull. Acad. Polonaise Sciences, 29, 317-322.

SYWUla, T., SUOMAlainen, E., SAURA, A. AND LOKKI, J. 1985. Genetic structure in natural populations of Ostracoda. I. Electrophoretic methods. Zeitschrift für zoologische Systematik und Evolutionforschung, 23, 194-198.

TETART, J. 1978. Les garnitures chromosomiques des Ostracodes d'eau douce. Trav. Lab. Hydrobiol., 69-70, 113140.

TRESSLER, W. L. 1959. Ostracoda. In Edmondson, W. T. (ed.) Freshwater Biology, 2nd edition, John Wiley and Sons, New York, pp. 657-734. 
VINYARD, G. 1979. An ostracod (Cypridopsis vidua) can reduce predation from fish by resisting digestion. Amer. Mid. Nat., 102, 188-190.

VRIJENHOEK, R. C. 1978. Coexistence of clones in a heterogeneous environment. Science, 199, 549-552.

WEIDER, L. J. AND HEBERT, P. D. N. 1987. Microgeographic genetic heterogeneity of melanic Daphnia pulex at a low arctic site. Heredity, 58, 391-399.
WEISMANN, A. 1880. Parthogenese bei den Ostracoden. Zoologische Anzeiger, 3, 82-84.

williams, G. C. 1975. Sex and Evolution. Princeton Univ. Press. 